\title{
Uma questão de ex/periência: antes do canto o en-/canto?
}

A matter of experience: before the achievement, the fascination

\author{
Ana Paula da Silvares \\ Renata Cristina Araújo Gomes
}

Resumo: Este é um ensaio dos registros/relatos dos pensamentos/diálogos dos/nos en/cantos que o espaço de trans-formação possibilita numa proposta de pensar e construir palavras e significados nos cantos da escola. O texto apresenta os desassossegos das vivências filosóficas de uma pesquisa-ação proposta por duas coordenadoras de área da Rede Municipal de Ensino, uma em Matemática e a outra em Filosofia para/com Crianças. Os contextos do en-canto são os espaços da formação docente na Universidade Federal do Espírito Santo, em um seminário de filosofiae um Centro de Educação Infantil, em duas turmas de crianças com 05 anos. O interesse deste exercício é perceber os percursos do/para re-pensar e des-construir os saberesfazeres docentes nos acontecimentos que dão sentido a igualdade das inteligências na/para emancipação intelectual dos sujeitos educacionais. Os em-cantos deste relato de experiência se confirmam em Larrossa $(2002 ; 2011)$ que nos aponta a experiência como uma trilha no caminho, um trajeto potente, um percurso de resistência no acontecimento, no afeto, significando o sujeito que nela se expõe, seus pensares e fazeres. Ranciére (2011) e Kohan (2000; 2007; 2009; 2015) nos convidam a re-pensar; res-significar as representações da experiência docente nos fazeres de experiência que interrompem a lógica provocando-nos a nos suspender na ex-posição à novidade, sem nos satisfazer com as memórias dos en-cantos outrora vividos, antes persegui-los como presença presente nas/para as práticas do ensinar e aprender nas e com as infâncias no esforço da igualdade das inteligências.

Palavras-chave: Experiência. Pensamento. Docente. Infância.

Resumen: Este es un intento de los registros / relatos de los pensamientos / diálogos de los / en los ángulos que el espacio de trans-formación posibilita en una propuesta de pensar y construir palabras y significados en los rincóns de la escuela. El texto presenta las inquietude de las vivencias investigación-acción filosóficas de una propuesta por dos coordinadores de área de la Red Municipal de Enseñanza, una en Matemática y la otra en Filosofía para / con niños. Los contextos del en-canto son los espacios de la formación docente en la Universidad Federal de el Espírito Santo, en un seminario de filosofia, y un Centro de Educación Infantil, en dos grupos de niños con 5 años. El interés de este ejercicio es percibir los recorridos del / para re-pensar y des-construir los conocimientos docentes en los acontecimientos que dan sentido a la igualdad de las inteligencias en la emancipación intelectual de los sujetos educacionales. Los entramados de este relato de experiencia se confirman en Larrossa $(2002$; 2011) que nos apunta la experiencia como un sendero en el camino, un trayecto fuerte, un recorrido de resistencia en el acontecimiento, en el afecto, significando el sujeto que en ella se expone, sus pensamientos y hacer. Ranciére (2011) y Kohan (2000; 2009; 2015) nos invitan a (re) pensar; (res) significar las representaciones de la experiencia de el instructor en los hechos de experiencia que interrumpen la lógica provocándonos a suspendernos en la posición a la novedad, sin satisfacernos con las memorias de los en-cantos otrora vividos, antes persíguelos como presencia presente en las / para las prácticas de enseñar y aprender en las y con las infancias en el esfuerzo de la igualdad de las inteligencias.

Palabra: Experiencia. Pensado. Enseñanza. La infancia. 


\section{Uma nota...}

Como deixar para lá o que se experimenta quando a infância te educa? Este texto, que toma a forma de um relato de experiência, tem a intenção de pensar, narrar e questionar os afetos e atravessamentos vivenciados por duas professoras em experiências de pensamento e em diálogos investigativos, por ocasião de encontros de (trans)formação, vivenciados na educação infantil e na universidade. Convida a um perguntar e perguntar-se sobre o que esse exercício do pensar faz conosco, com os nossos saberes e fazeres e o que fazemos com isso quando aprendemos e ensinamos. Essa é uma escrita-possibilidade de pensar a experiência como um tempo-percurso intenso e inventivo; como um canto (um som e um espaço) que, ao nos convidar ao retorno, revela-nos caminhos tão familiares como se os trilhássemos pela primeira vez.

A proposta é dialogar com a educação básica, perceber as marcas, os acontecimentos, os trajetos que nos impulsionam para além das fronteiras da pedagogização; que ultrapassem os limites das cartilhas, dos programas e sistemas ao perceber, refletir, enxergar e escutar o sujeito como humano, palavra, sentido. A este respeito nos apoiaremos nas ideias de Larrosa (2002; 2011), Rancière (2011) e Kohan (2000; 2007; 2009; 2015), autores que nos inquietam rumo a re-ver, re-pensar e (des)construir saberes fazeres docentes nos cantos de uma formação cujo princípio é o diálogo entre os iguais.

O artigo traz na trajetória das duas docentes a possibilidade de re-visitar a escola de outros modos e experienciar outros afetos e atravessamentos que têm as crianças como formadoras, ensinantes aprendizes que, sem a pretensão de ensinar, desloca o ensino e aprendizagem rumo ao acontecimento, ao improvável.

\section{Os intervalos de uma composição: en-canto da alma atormenta?}

"Só a alma atormentada pode trazer para a voz um formato de pássaro" (Manoel de Barros, 1996, p. 75). 
"Precisamos voltar para a escola!" Foi assim que o en-cantar se principiou. Quem precisa voltar? Por que precisa? Para qual escola voltar? Quem volta é o mesmo que se ausenta? Aquela voz inquiridora não para de ecoar, inquietar e, no en-canto o pensar. Silêncio. Em tormento, um en-canto que dá asas ao tirar a voz para en-cantar no som de suas asas.

Este en-canto - aquele instante que nos aproxima do pouco frequentado, que nos desloca no exato espaço-tempo onde as vozes compõem uma harmonia que, dissonante resgata o sentido, algum sentido consoante entre o saber, o fazer e o ser docente - é "experienciado" no ano de 2017, no Seminário "Filosofia com Crianças, Infância do Pensar: movimentos nas escolas públicas de São Mateus", no qual a Universidade Federal do Espírito Santo (UFES), em parceria com a Secretaria Municipal de Educação de São Mateus, ES (SME) propõem um espaço/tempo para o diálogo entre duas docentes-pesquisadoras da Universidade do Estado do Rio de Janeiro (UERJ) - a professora Doutora Vanise de Cássia de Araújo Dutra Gomes e a professora Mestre Edna Olimpia Cunha e os professores que atuam com a Filosofia para e com Crianças na Rede Municipal de Educação.

Os encontros ${ }^{1}$ proporcionaram diálogos, em que as vozes das experiências que se dão no Núcleo de Estudos de Filosofias e Infâncias (NEFI) e aquelas que ecoam nas vivências da/na formação continuada com professores que atuam com a Filosofia para/com Criança de 02 a 10 anos de idade (as crianças da Educação Infantil e do Ensino Fundamental em seu primeiro segmento) se descobrem, se questionam, investigam-se na conversa, na abertura dos "saberesfazeres" que os atravessam.

Neste lugar-movimentos os sujeitos se propuseram encontrarem-se em rodas de conversas, em oficinas e relatos em que a experiência do pensamento superava a exposição de saberes, de fazeres. Foi nessas práticas que um tormento em som nos enredou nas composições de um pensamento que ao se pensar desassossegava-se, deslocava-se "sabendo de soslaio", desejoso de presenciar a realidade e aprender com ela, com a realidade que nos parecia tão

\footnotetext{
${ }^{1}$ Evento experienciado entre os dias 31/11/2017 e 02/12/2017, no auditório do Programa de Pós-graduação em Ensino na Educação Básica (PPGEEB), do CEUNES/UFES, São Mateus, ES.
} 
familiar, com as proximidades, domínios que ao nos pertencer, nos escapava. A proximidade com os encontros que precediam esse instante se tornou estranha, e a intimidade... distante. Era urgente se expor, compreender a experiência filosófica como um fazer/um viver em trans-formação pelo/no diálogo do saber, fazer e ser docente com/nas/para as realidades e sujeitos educacionais.

Foi a beleza, a harmonia dos sons do/no tormento da alma de duas docentes, (uma pedagoga e uma matemática) que fizeram da experiência filosófica um canto, um espaço de des-encontros das vozes, dos pensares, dos fazeres; um tempo para ouvir, pensar a realidade nas intimidades com os sentidos que viver em diálogo compõe; um querer saber quais aberturas/sentidos a experiência filosófica proporciona à trans-formação dos sujeitos educacionais.Nela/a partir dela/com ela ensinamos e/ou aprendemos? Um desassossego do pensamento que investiga... se investiga. $O$ en-canto, o encontro das vozes, esse ouvir-sentir a realidade trans-formadora no exercício filosófico do diálogo que inquietou, desassossegou, atravessou filosofia e matemática, unindo-as em direção a escola, no conferir do quanto o "saberfazer" docente está envolto na/com a experiência e quanto desta prática reflete e transforma as realidades.

Compor a experiência como uma trilha no caminho das sistematizações educacionais, que provoque os en-cantos, convide a (re)pensar, a (des)construir os "saberesfazeres" docentes pelo viés da emancipação das inteligências, pelo diálogo compositor das notas, das vozes e dos cantos que produzem/apresentem a escola como palco/cenário de uma educação que seja ela mesma emancipadora, que encontra seu sujeito nas infâncias que se expõem no aprender e ensinar. Trata-se de envolver-se, vivenciar o contexto da prática filosófica na/com a infância, refletindo a igualdade nos movimentos do pensar investigativo, inventivo da educação, da infância, da filosofia.

Uma nota. Silêncio. Uma melodia. Composição. Pensar a escola e os "saberesfazeres" docentes é dialogar, investigar, se investigar nela, com ela. Precisávamos de espaço, preencher os espaços em nós, pensar os intervalos sonoros que as vozes em nós e fora de nós revelaram. Pensar o silêncio e as 
composições, as palavras e os sentidos enquanto interferimos na realidade que estes configuram em nós, em outros.

En-cantadas, nos expomos à abertura do possível em Larrosa (2002; 2011), que nos aponta a experiência como um convite a nos (re)ver e em padecimento (re)pensar e (des)contruir os saberesfazeres docentes no viés das aproximações e distanciamentos que as palavras, a intimidade e relações com elas nos permitam. Rancière (2011) traduz essas relações na emancipação das inteligências como modo de estar/ser docente na força em (re)pensar em si como sujeito semelhante a qualquer outro, consciente do poder que o exercício do pensar investigativo institui. Kohan (2000; 2007; 2009; 2015) nos permite (re)pensar; (res)significar as representações das práticas docentes nos fazeres de experiência que interrompem a lógica, provocando-nos a nos suspender na ex/posição da novidade dada nos diálogos de uma experiência do pensamento, na qual a suspensão das vontades, dos saberes e fazeres pela ex/periência de (trans)formação no afeto da palavra potente que emancipa o pensamento e a linguagem.

“Uma questão de ex/periência: antes do canto o en-/canto?"é uma tentativa de relatar os desdobramentos da experiência filosófica na infância docente, narrar os acontecimentos, as composições, os en-/cantamentos que nos levaram à realidade da escola, ao desassossego da nossa realidade, ao canto inquietante, dissonante, com o qual o saber, fazer e ser docente se compõem movimentos dos percursos que se apresentam íntimos e distantes, conhecidos e desterritorializados.

\section{O en-/canto: orquestrar para compor? Compor para experiência?}

"Quando eu era professora da pré-escola não ensinava nada, não. Eram eles, as crianças que me ensinavam, só que eu não tinha caído a ficha antes disso. Eu tinha uma vivência da educação infantil, mas a experiência me mostrou que dentro da minha vivência tinha experiência e eu não conseguia enxergar, nem viver. Eu só me dei conta de que eram os meninos que me ensinavam quando passei pela experiência com Vanise e Edna" (R.C.A., Comunicação pessoal, 31 nov. 2017). 
Foi assim que a professora Renata ${ }^{2}$ decidiu me en-cantar. Foi assim, que depois de vivenciar a experiência filosófica composta para o seminário "Filosofia com Crianças, Infância do Pensar: movimentos nas escolas públicas de São Mateus", ela me atraiu, com "a forma de pássaro" que aquele som inquieto de seu pensamento ressoava.

Era urgente voltar para a escola. Era desejoso viver os en-cantos que as vozes da experiência produzem em seu contexto, em sua realidade. Era preciso possibilitar a experiência e viver experiências. Experimentar, permitir que algo nos acontecesse, nos tocasse, nos modificasse em diálogo - palavras que produzem sentidos, criam realidades. Palavras que têm poder, têm força e fazem coisas conosco enquanto fazemos coisas com elas (LARROSA,2002, p.21) com os sujeitos educacionais, seus saberes, seus fazeres, seus modos de ser e habitar a escola.

Não eram os mesmos sujeitos que estavam voltando para a escola. Fazer, viver em experiência é se expor aos espaços-tempos peculiares da educação e às heterogeneidades que se apresentam e desenvolvem-se com e nos atos do ensinar e aprender. A busca por significados se apoderou de nós e orquestrávamos uma composição que se constituísse na/com/para a prática investigativa no diálogo que questiona o ser, o fazer, o pensar educacional, permitindo um desenvolvimento cognitivo no acontecimento, nas mudanças que os sujeitos experienciam no e para o saber.

Quem volta para a escola tem interesse em entender as vivências matemáticas com/das crianças de 05 anos em fase escolar e (re)pensar, (des)construir os saberesfazeres que limitam as inteligências, viabilizando o conhecimento nas potências do pensar inquiridor, nutrindo a curiosidade na experiência do diálogo que, sendo filosófico, possibilita uma outra relação com os saberes na intimidade, na amizade com o conhecimento.

A experiência de retorno à escola se compõe como um saberfazer em diálogo. Na palavra que observa atentamente o movimento, a relação que os sujeitos têm com as vozes e estas com eles. É uma proposta em vivenciar a

\footnotetext{
2 Professora e coordenadora da área de Matemática da Rede Municipal de Educação em São Mateus; professora da Educação Infantil desta mesma Rede neste período.
} 
Matemática na Educação Infantil com/na experiência de pensamento, um movimento do pensar que atravessa a vida de quem a prática, no sentido de permitir-Ihes que seu pensar filosófico possa emergir, liberando esse pensar daquilo que ele tem de pronto, de fixo, de determinado, de previsível, de repetível, de não-pensar (KOHAN, 2000, p. 31-33).

Não há nada que se esperar quando se quer viver em experiência, há que se intensificar a atenção ao encontro das vozes, dos pensamentos que se elegem e se moderam na pergunta, na afirmação, na palavra e em sua força/poder que desassossega e liberta, palavra/pensamento que inaugura $o$ novo, o indeterminado, o imprevisível, o irrepetível.

A experiência é única. Ela é singular, pessoal ainda que os acontecimentos sejam o mesmo para um coletivo a experiência é sempre uma, intransferível, e não se repete. É o como o sujeito acolhe o saber. É o ver, ouvir e sentir, é a atenção que cada sujeito dá ao conhecimento. É a permissão não permissiva em que o acontecimento faça algo com o seu modo de ver, sentir, pensar e viver a realidade.

A experiência é questão porque é interrogativa, como o é a filosofia. É uma relação intima com o não-saber, com os en-cantos e cantos que a realidade apresenta, permite, confronta, resiste, questiona, duvida. É exposição na pergunta, na investigação que potencializa os acontecimentos na ação que interroga.

A realidade do aprender e ensinar tem sentido na experiência, sentidos que se alteram, se modificam, ganham outros significados nos acontecimentos da educação, da infância e da filosofia. Ela nos interrompe, proporciona o encontro no parar, no ouvir, no sentir singular, atencioso dos acontecimentos. A experiência que escapa do saber, das vontades, das intenções compõe o canto onde en-cantadas nos encontramos conosco... e com outros. 


\section{En-canto: no canto}

Em São Mateus o canto ${ }^{3}$ da educação infantil se abre para os en-/cantos da filosofia desde o fim da década de 90. Foi para lá que retornamos orquestrando as composições que possibilitassem a experiência, o viver em experiência, ao invés de dominarmos o canto, fomos en-cantadas. Experienciamos os movimentos de um pensar que nos tocava, de vozes que ao resistir as naturalidades nos modificavam. Percebíamos os cantos e en-cantos da infância que exterior a nós, escapava ao controle, revisitando as previsões e hipóteses planejadas, desconstruindo os resultados esperados. As intenções que tínhamos deixaram de ser nossas e fugia a tudo aquilo que estávamos preparadas para dizer, pensar e fazer.

Os outros que diante de nós se apresentavam traziam gestos, sons da infância, dos inícios, da novidade. A escola que encontramos aceita a proposta de viverlpermitir a experiência em dois grupos de crianças, designados aqui como turma M e turma $\mathrm{H}$.

Vinte e oito meninos e meninas en-cantadores nos recepcionavam em sua rotina, resistindo-a com uma voz ressonante, nolcom o canto que, destoando-a, a torna acessível, harmoniosa para a experiência.

Com a proposta de nos apresentar o espaço, a escola que não conhecemos, um despretensioso diálogo se inicia entre nós e eles que, de pé, nos rodeiam um a cada vez, criando um coletivo interessado, envolvido, e nos en-Icantando foram nos encontrando, nos trazendo para fora de nós com seus gestos afetuosos.

"Você veio dar aula, tia?" (Questiona a aluna F.)

"É isso que vocês fazem aqui? Aula?" (professora Ana ${ }^{4}$ procura saber.)

\footnotetext{
${ }^{3}$ Utilizamos o processo de homonímia na utilização da palavra "Canto" nesse texto. Ora o leitor poderá compreender ser o canto como um lugar, um espaço retirado onde os limites se encontram e nos movermos até ele é nos distanciarmos do centro ou ainda, ser a melodia de um som que nos en-canta, nos convida a ouvir mais devagar, a dar atenção a voz, a língua da experiência.

${ }_{4}^{4}$ Pedagoga e coordenadora da área de Filosofia para/com Crianças da Rede Municipal de Educação em São Mateus neste período.
} 
Com a cabeça se movimentando em gesto afirmativo, a aluna $\mathrm{F}$ continua:

"É. A gente senta nas cadeiras e espera. Ai, a tia vem e ensina para a gente ler as letras, as palavras" (Explica a aluna F.).

"E, você lê?" (Continua a professora Ana).

"Não, né! Eu desenho, brinco com a massinha e com a tinta. Mas, eu não sei ler!"(A aluna $F$ apresenta suas conquistas).

"Você veio dar aula?" (O aluno G. enfatiza a pergunta se unindo a nós em diálogo).

"Eu gosto de desenhos, tintas e massinhas, sabe? Eu queria brincar com vocês, conversar mesmo" (A professora Ana percebe que esses fazeres são os instantes da aula que promovem um certo acontecimento).

"Ai, tem que ir para a rodinha primeiro" (Aluno G. pega e conduz a professora pela mão).

Os outros deslocam a atenção do que estavam fazendo com os outros que por ali estavam a conhecer a escola e começam a se organizar para a rodinha.

"Quer que faz? É bem legal!" (Aluna F. garante bem animada sobre a rodinha.)

"Se é legal pra vocês, eu quero" (A professora animada se senta. Todos os outros também).

Depois, eu te levo no parquinho, então. E onde a gente come a comidinha e brinca, tá? (o aluno Gui sugere segurando a outra mão) (A.P.R.Silvares, registro pessoal, 17 mai. 2018).

Foi assim que principiamos nosso conhecimento das escolas que aquele Centro de Educação Infantil abrigava. A escola que as crianças habitavam, resistindo em suas experiências do fazer-se criança, deslocando-se, deslocando-a do ler e escrever pelo afirmar do pensar como seu princípio, defendido pela maestria inventiva afirmada em Rodriguez por Kohan (2015). A escola da forma preferida para a aula, preterida para a experiência do saber na experiência lúdica que sensibiliza para pensar fora das mesas, das cadeiras, que convida para a roda - um canto, um espaço-tempo de viver o "legal", o acontecimento para além do ler, o deixar-se tocar, mudar e despretensiosamente ser ele mesmo a escola, a inteligência, o pensamento, as palavras que realizam 
o algo em nós enquanto com ela vamos (desłre)construindo as realidades do saber, do fazer, do ser sujeito (não objeto) educacional.

Neste fazer escola se abrem as portas, ao outro, ao desprezado. Este é convidado a dialogar em sua própria língua; é considerado um igual, é apreciado em sua força, sua capacidade, sua integridade, são oferecidas a ele as condições materiais e afetivas para aprender a pensar e a viver com ele; experimentar um trabalho e uma vida comum; trabalha-se na sua atenção; estimula-se a sua vontade; ensina-se a ele a língua do outro, e ele é também ouvido em sua própria língua (KOHAN, 2015, p.96).

Foi gentil o convite, as condições que esta escola nos ofereceu. A escola desvelada no canto das docentes, e revelada no en-canto da infância nós fomos a descobrir, nos descobrir em outras línguas, em nossa língua, nos afetos da/na experiência do pensamento, do diálogo, da palavra.

\section{Ecos no canto - há en-cantos?}

No poder, na força da palavra, o significado da experiência vem se constituindo, nos compondo em/com/na palavra que pensa, questiona a realidade pelo pensar e comunicar o pensamento na igualdade das inteligências, a partir do diálogo entre os sujeitos. O en-canto se dá na palavra vocalizada na experiência com outros, experimentada no diálogo interior favorecendo a transformação na vivência do próprio acontecimento.

No poder, na força do pensar, na atenção do sentido ao que somos e ao que nos acontece vem se iniciando, nos iniciando, nas res-sonâncias do diálogo escolar docente, mas e, principalmente, nas dis-sonâncias dos/nos diálogos da infância que aceitam na escuta atenta e no perguntar, os en-cantos; os cantos que ecoam em nossos pensamentos, que justifica a experiência de um pensar entre /com os sujeitos de nossa realidade.

Às vezes, na ação, ou na prática, algo me passa. Mas esse algo que me passa não tem a ver com a lógica da ação, ou da prática, mas, justamente com a suspensão dessa lógica, com sua interrupção (LARROSA, 2011,p.22).

Educar deve significar a educação nos acontecimentos da emancipação, que segundo Rancière (2011) é um pensar sobre quem somos e o que fazemos na evocação do próprio sentido de uma prática no e para o ensino-aprendizagem 
capaz de promover encontros do sujeito consigo e com outrens que, ao se encontrarem, não se usurpam de experienciar outros espaços/tempos/sujeitos.

A educação organizada para que nada aconteça se encontra com a experiência de pensamento que "exige autonomia por todas as partes (...) autonomia do professor ante os marcos institucionais que o regulam; autonomia de quem aprende ante a quem ensina e os outros aprendizes" (KOHAN, 2009, p. 70-71); nas exigências da autonomia ecoa uma educação filosófica.

Nossa proposta é uma educação organizada para nos marcar, que ultrapasse os limites da escola, das cartilhas, dos programas e sistemas olhando e vendo o sujeito como humano, palavra, experiência e sentido. Silêncios e ecos. Um lugar onde tudo se organize para tocar, acontecer, afetar, en-cantar. Ela é o lugar onde as palavras são significadas nos saberesfazeres que apontam a urgência de vivências que se interrompam, que se deixe afetar pelas/nas igualdades da inteligência que o encontro com/na infância confirma. Que pare para pensar, olhar, escutar e sentir os detalhes de um diálogo em que os saberes se encontram sem cerimônias e abertos capturam o instante em que aprender é ensinar e o faz com/nos/em afetos, se (trans) formando, (res) significando-se, afetando-se.

A experiência é pausa, um demorar nos detalhes que interrompe opinião, saber, vontade, mecanicismos da práxis num ato de solidariedade consigo e com outros. Deslocando a atenção da partitura escolar para as ausências, intervalos e possibilidades de novas composições nas pautas do devir educação, filosofia e infância.

A experiência filosófica é um canto de resistência, de afirmação da liberdade. É o canto do pensamento que se emancipa na igualdade das inteligências. Não há amor e/ou amizade sem o encontro com o outro, em outro. Não há amor pelo conhecimento, tão pouco amizade pelo saber se esta relação não se der na palavra que determina o acontecimento, a passagem. A palavra que é linguagem, é pensamento, significado da realidade que ao ser construída em/no coletivo é também a possibilidade de se fazer experiência fora de si, na dependência da palavra e do sentido do outro que te liberta do eu (SILVARES e GOMES, 2018, p. 254). 
Pensar/vivenciar essa experiência requer um professor que, conforme Kohan (2015, p.89):

[...] pensa nos outros, e não em si mesmo; se busca saber é para que outros possam saber. .... ele é o que marca a primeira relação de quem aprende com o aprender, porque aprendendo o que ele ensina, ou melhor, quando se aprende essa relação que ele ensina com o aprender, aprendem-se todas as outras coisas, e sem essa aprendizagem nada poderá ser aprendido que valha a pena.

\section{Para continuar em en-canto...}

"Para emancipar a outrem, é preciso que se tenha emancipado a si próprio. É preciso conhecer-se a si mesmo como viajante do espírito, semelhante a todos os outros viajantes" (Jacques Rancière, 2011, p. 57).

De volta ao princípio, lugar onde a vivência dotada de experiência não foi sentida/experimentada. Agora infantes na busca pela emancipação nos saberes fazeres de uma experiência do pensamento no diálogo, cujas palavras em seu poder e força constituem os sujeitos, os espaços e os tempos educacionais sem a pretensão de converter ou salvar a escola e aqueles que a habitam e/ou por ela se deslocam, antes padecer no tormento da liberdade que encanta nos cantos da liberdade em tormento.

Continuamos a pensar, a questionar e a nos questionarmos o que pode uma experiência de pensamento em diálogo filosófico quando a infância é quem nos educa? O que esse exercício faz conosco, docentes na escola? O que fazemos com o que nos é feito quando somos afetados na e em experiência?

O convite é para nos envolver com os sons, com as vozes e pelos cantos que nos trazem de retorno para explorar a novidade e nos aventurar na inventividade de um aprender e ensinar outro. É um descobrir-se docente infante, inacabado, em deslocamentos intensivos, inventivos por uma educação entre e com iguais, uma educação popular, onde os sujeitos do conhecimento sejam sujeitos da experiência. 
Assim, continuamos a perguntar e nos perguntarmos... quem volta à escola? Que não seja o mesmo. Porque volta à escola? Que seja a escola o canto de novos acontecimentos, o encanto em novos porquês. Para qual escola voltar? Para aquela apresentada/vivenciada pela/nas infâncias, a escola do devir, da resistência, da palavra. Quem volta é o mesmo que se ausenta? É o tormento da ausência que garante a liberdade do retorno e a possibilidade de se desconstruir e reinventar-se.

\section{Referências}

LARROSA, J. Notas sobre a experiência e o saber de experiência.Revista Brasileira de Educação, n. 19, Jan./Fev./Mar./Abr. 2002.

Experiência e Alteridade em educação.Revista Reflexão e Ação.19 (2),2011, p. 4-27.

BARROS, M. de.(1996). Livro sobre o nada. 3ed. Rio de Janeiro-São Paulo: Editora Record, 1996.

KOHAN. W. O. O mestre inventor: relatos de um viajante educador. Belo Horizonte: Autêntica Editora, 2015.

Filosofia: o paradoxo de aprender e ensinar. Belo Horizonte: Autêntica Editora, 2009.

Filosofia na escola pública. Petrópolis: Vozes, 2000.

RANCIĖRE, J. O mestre ignorante. 3ed. Belo Horizonte: Autêntica Editora, 2011.

SILVARES, A.P.R.; GOMES, R.C.A. Quando pensar é só um cantinho? Uma questão de ex/periência. Filosofar: resistir nas escolas. Anais I Seminário Internacional Educação, Filosofias, Infâncias. Volume I, 2018, p. 245-256.

\section{Sobre os autores}

\section{Ana Paula Rocha Silvares}

Email: anapaula.silvares@hotmail.com

Mestranda do Programa de Pós-Graduação em Ensino na Educação Básica, CEUNES-UFES. Licenciada em Pedagogia (2008). Pedagoga da Prefeitura Municipal de São Mateus no exercício da Coordenação de área de Filosofia para/com Crianças.

\section{Renata Cristina Araújo Gomes}

Email: renatacris_araujo@hotmail.com

Mestra em Ensino na Educação Básica do Ceunes-UFES. Graduada em Matemática. Docente da Rede Municipal de Educação de São Mateus, ES, onde coordena a Área de Matemática e Ensino Fundamental II. 